\title{
Bizarre Radiographic Finding of Intraoral Neurofibroma: A Case Report
}

\author{
MAYANK JAIN', SALONI DEOL JAIN²², PRITI GUPTA³
}

Neurofibroma(NF) is one of the common well known autosomal dominant inheritable entity with a prevalence of one per 3000 people. Clinically, there are two types of NF:NF 1 with $90 \%$ occurrence along with 7 subtypes and NF2. It is a genetic disorder and benign peripheral nerve sheath tumor. It has a neural origin with presence of café -au-lait spots along with multiple nodules over the skin and all over the body. It might be associated with bone malformation and sometimes the central nervous systems is also involved. Diagnosis of neurofibroma is based on clinical criteria. The frequency of oral manifestations is debated in the literature. Some authors report a frequency of $4-7 \%$ of cases, whereas others suggest that these manifestations are present in up to $72 \%$ of cases. Here the purpose of this case report is to review the disease with intraoral clinical and radiological findings found in a patient having a bizzare radiographic finding of Intraoral Neurofibroma (NF).

\section{INTRODUCTION}

Neurofibroma(NF) is a benign peripheral nerve sheath tumor that arises from Schwann cells and perineural fibroblasts. ${ }^{1,2}$ Scientific literature describes two clinical forms of neurofibromatosis: peripheral(type I); and central(type II). ${ }^{3,4}$ It is a genetically-inherited disorder that affects the development and growth of nerve cell tissues and also causes cafe-au-lait spots on the skin, dysplastic changes of the skin, bones, blood vessels, endocrine system along with nerve tissue. An autosomal dominant chromosome mutational disorder, Von Recklinghausen neurofibromatosis type I (vRNF-1), first described by Frederick Von Recklinghausen in the year $1882 .{ }^{4}$ This form of the disease is also known as Von Recklinghausen's disease of the skin and authors document the prevalence in $85-97 \%$ of cases. It is generally observed that $50 \%$ of all patients have negative or non-contributory family history and apparently represent new mutations. ${ }^{5}$

Intraoral findings of NF are quite uncommon but due to similar clinical appearance with some other inflammatory and neoplastic conditions, they deserve special attention. It has been reported in the literature that only $50 \%$ of the NF1 patients have a positive family history of the disease. ${ }^{6}$ It mainly appears in the third decade of life although, its occurrence between 10 months year olds as well as 70 year old people have been reported by various authors. Any preference of sex is reported contradictorily. ${ }^{7}$

\section{CASE REPORTS}

Case 1: A 38 year old male patient visited the department of Oral and Maxillofacial Medicine and Radiology, I.T.S. Dental College and Hospital, Greater Noida, Uttar Pradesh with a chief complaint of missing teeth since 2-3 months. Upon examination, numerous small to large nodular growth of the skin varying in size was present throughout the body. A Brownish small macular appearance was also observed all over the body along with the presence of Café-au-lait spots over the trunk area (Figure 1,2,3\&4). There was no positive family history is present. Subsequently, extraoral examination revealed the presence of frontal bossing. Whereas, Intraoral examination revealed generalized recession of attached gingiva with diffuse swelling present in both maxillary and mandibular anterior tooth region. On the basis of clinical appearance of disease, a diagnosis of neurofibromatosis type one was established.

Upon Radiological Examination, An Orthopantomograph (OPG) reveals multiple unilocular and multilocular well-defined radiolucencies with corticated border present with respect to $46,47,48$ tooth region involving the whole ramus and angle of the mandible on the right side. Also, an ill-defined radiolucency is observed in respect to 36,44 and 45 tooth region with widened mandibular nerve having a faded appearance on the right side of the mandible. Degenerative changes of the condylar head on both sides with deepening of the sigmoid notch 
and shortening of the ramus of mandible is present on the right side of the mandible. An enlarged mental foramen is also seen bilaterally. The Mandibular nerve and canal is not highly appreciable in the OPG. The appearance of multilocular radiolucency mimics other odontogenic cyst such as Keratocystic odontogenic tumor (KCOT) (Figure 5).

On the contrary, enhanced Computed Tomography (CT) of the face and neck region reveals a well-defined radiolucency with respect to the mandibular nerve and it seems to originate from the same. This confirms the diagnosis of the neurofibromatosis type I (Figure 6).

Case 2: A 30 year old female patient visited to the department of Oral and Maxillofacial Medicine and Radiology, I.T.S. Dental College and Hospital, Greater Noida, Uttar Pradesh with a chief complaint of decayed teeth since 6 month. Upon examination, multiple sessile to pedunculated nodular growth was present over the whole body (Figure 7a, 7b). The patient's head was tilted towards right side and she could not keep it erect (Figure 7c). The patient also gave a history of disturbances in vision and headache since 6 years. Intraoral examination revealed diffuse, soft, nontender in consistency swelling is present over the left side of the palate which measures approximately 20 millimeters $(\mathrm{mm})$ to $25 \mathrm{~mm}$ in diameter with a normal mucosal color on its surface.

A positive family history was also given by the patient with her one female child having the presence of café-au-lait spots all over her skin. A PA(Posterioanterior) view of the head and neck and chest $x$-ray reveals the deviation of the cervical vertebrae towards right side suggestive of cranio-vertebral anomalies, whereas an OPG showed no evidence of radiolucency in the palate or any other abnormal finding(Figure 8).

\section{DISCUSSION}

$\mathrm{NF}$ is transmitted as an autosomal dominant disease, which is shown to be related to a mutation in the pericentric proximal gene locus on chromosome ${ }^{17}$. About one half of all the cases are hereditary while the other half is thought to be due to a spontaneous mutation. ${ }^{8}$ The pathogenesis is thought to be due to neurofibromin, the $\mathrm{NF}_{1}$ gene product, which is a tumor suppressor that dampens products or ras protooncogenes and its loss may contribute to tumor progression when gene mutation occurs. ${ }^{9}$

Holt $^{10}$ defined neurofibroma as a hereditary hamartomatous disorder, probably of neural crest origin, involving not only neuroectoderm but also endoderm, with the potential of appearing in any organ system of the body.

It may be considered that NF may include a spectrum of diseases ranging from hamartomas of neural and various mesodermal tissue to benign or malignant neoplasm."

NF I, also known as Von Recklinghausen's disease, is one of the most commonly observed autosomal dominant inherited disorders, with an incidence of one in 3000, which has been reported in all races, with no definite gender predilection. ${ }^{12}$

Despite the innumerous advances in the field of molecular biology, the diagnosis of both NF I and NF II are still based on clinical criteria. The National Institutes of Health Consensus Development Conference has suggested clinical criteria diagnostic of NF I and NF II $^{13}$ or 'Discrete' or 'Localized' and 'Plexiform' neurofibromata. A localized neurofibroma arises from a single site along a peripheral nerve and presents as a focal mass with well-defined margin with superficial origin or may involve deeper peripheral nerves. Localized neurofibromata are the most common type of neurofibromata that occur in NF1 patients. The neurofibromata are rarely(if ever) present at birth and usually appear in late childhood or early adolescence. The number of localized neurofibromata tends to increase with age, and varies widely from person to person due to differences in individual characteristics. $\mathrm{NF}_{1}$ patients may have few, hundreds or even thousands of localized neurofibromata which are found mostly on the skin. In the head and neck region, commonly affected sites are the scalp, cheek, neck, and oral cavity. Such similar findings have been reported by Cunha et al. ${ }^{14}$ and Anand Kumar et al. respectively. ${ }^{15}$

A plexiform neurofibroma is a peripheral nerve sheath tumor that extends along the length of a nerve. This lesion may also occur superficially or 
deeper inside the body. It is documented that Plexiform neurofibromata are a major source of morbidity associated with NF1 mainly due to their tendency to grow to large sizes and cause disfigurement in appearance of an individual. They may extend for some distance along a nerve while involving multiple nerve branches. The fifth, ninth and tenth nerve are the cranial nerves most involved in plexiform neurofibromata. ${ }^{16}$

Oral manifestations were found in $72 \%$ of the patients with $\mathrm{NF}$, in a study performed by Shapiro et al. $^{17}$ According to a survey performed by D'Ambrosio et al., $66 \%$ of the patients suffering from NF1 had at least one intraoral manifestation of the disease and $58 \%$ presented with manifestations in the maxilla and the mandible, which were detected with the help of panoramic radiographs(OPG). ${ }^{18}$ Neurofibromas may appear in any tissue, both soft or hard in the oral cavity. The most commonly affected site is the tongue ${ }^{19,20,21,22}$ but interestingly in none of the cases reported in the present report, had the presence of tongue lesions associated with NF1. Shapiro et al. stated that gingival involvement is only $5 \%$ in cases with $\mathrm{NF}_{2} 3$ and in agreement, one of the reported cases in this study had palatal swelling (Case 2).Also, both the cases reported in the present study had associated café-au-lait spots over the skin. Apart form the tongue, which is the most commonest site in NF, other affected sites include lips, palate, buccal mucosa, gingiva, floor of the mouth or the pharynx. ${ }^{25}$

Oral radiographic findings unique to NF include lengthening, rarefaction and or narrowing of coronoid and articular process of the Tempromandibular Joint (TMJ), deepening of sigmoid notch, the presence of enlarged mandibular canal, mandibular foramen and mental foramen. All of these above mentioned findings were present in the cases reported in this study. Other associated radiographic findings which were not present in the documented cases are shortening of the ramus, notching of the inferior border of the mandible and asymmetrically formed maxillary sinus. ${ }^{25}$

Histologically, neurofibromas are composed of a mixture of Schwann cells, perineurial cells, and endoneurial fibroblasts, which are not capsulated. ${ }^{26}$ Interestingly, Schwann cells account for about 36 to $80 \%$ of the lesional cells present and these constitute the predominant cellular type usually having a widened nuclei with an undulated shape and sharp corners. In an electron microscope image, Schwann cells can be seen embracing the axons and can be highlighted by silver or acetylcholinesterase staining and/or immunohistochemical techniques when using the optic microscope. It is estimated that 0.7 and $31 \%$ of the cells are perineurial in origin and in very few cases, these types of cells can predominate. ${ }^{26}$

It is advised that genetic counselling should be done for such cases with the requirement of a long term follow-up. Till date, there are no treatment guidelines are present. The treatment option involves surgical removal of the lesion that too, for esthetic purposes. In cases with a rapid increase in size of the neurofibroma and presence of pain, the probability of malignant transformation must be considered. ${ }^{26}$

\section{REFERENCES}

1. Geist JR, Gander DL, Stefanac SJ. Oral manifestations of neurofibromatosis types I and II. Oral Surg Oral Med Oral Pathol 1992;73:376-82.

2. Shapiro SD, Abramovitch K, Van Dis ML, Skoczylas LJ, Langlais RP, Jorgenson RJ, et al. Neurofibromatosis: oral and radiographic manifestations. Oral Surg Oral Med Oral Pathol 1984;58:493-8.

3. Cunha KSG, Barboza EP, Dias EP, Oliveira FM. Neurofibromatosis type I with periodontal manifestation. A case report and literature review. Br Dent J 2004;198:457-60.

4. Bongiorno MR, Pistone G, Aricò $M$. Manifestations of the tongue in neurofibromatosis type 1. Oral Dis. 2006;12:125-9.

5. Neville BW, Damm DD, Allen CM, Bouquot JE. Oral and Maxillofacial Pathology. 2nd ed. Philadelphia: Elsevier; 2002. pp. 457-61.

6. Ghalayani P. Neurofibromatosis type I (von Recklinghausen's disease): A family case report and literature review. Dental Research Journal 2012;9(4): 483-88.

7. Gomez-Oliveira G, Fernandez-AL, MartinSastre R, Patino-Seijas B, Lopez-CedrunCembranos JL. Plexiform neurofibroma of the 
cheek mucosa. A case report. Med Oral 2004; 9:263-7.

8. Marx RE, Stern D. Benign Soft Tissue Tumors of Mesenchymal Origin. Oral and Maxillofacial pathology: A rationale for diagnosis and treatment. Quintessence Publishing 2003. p. 4149 .

9. Joel LS. Genodermatoses: A clinical guide to genetic skin disorders 2/e. Lippincott Williams and Wilkins Inc; 2007. p. 167-8.

10. Holt JF. Neurofibromatosis in children. AJR Am J Roentgenol 1978;130:615-39.

11.Lee L, Yan YH, Pharoah MJ. Radiographic features of the mandible in neurofibromatosis: A report of 10 cases and review of literature. Oral Surg Oral Med Oral Pathol Oral Radiol Endod 1996;81:361-7.

12. Güneri EA, Akoğlu E, Sütay S, Ceryan K, Sağol $\mathrm{O}$, Pabuçcuoğlu U. Plexiform neurofibroma of the tongue: A case report of a child. Turk J Pedediatr 2006;48:155-8.

13. Gutmann DH, Aylsworth A, Carey JC, Korf B, Marks J, Pyeritz RE et al. The diagnostic evaluation and multidisciplinary management of neurofibromatosis 1 and neurofibromatosis 2 . JAMA 1997;278:51-7.

14. Cunha KSG, Barboza EP, Dias EP, Oliveira FM. Neurofibromatosis type I with periodontal manifestation. A case report and literature review. Br Dent J 2004;196(8):457-6o.

15. Anand KC, Jagat Reddy RC, Gupta S, Laller S. Oral hamartomas with von Recklinghausen disease. Ann Saudi Med 2011; 31(4): 428-30.

16. Komerik N, Kirzioðlu Z, Ulu G, Kapucuoglu N. Neurofibroma of the mandible in a child with Neurofibromatosis type 1. Arch Oral Sci Research 2011; 1(2):95-9.

17. Shapiro SD, Abramovitch K, van Dis ML, Skoczylas LJ, Langlais RP, Jorgenson RJ, et al. Neurofibromatosis: Oral and radiographic manifestations. Oral Surg Oral Med Oral Pathol 1984;58:493-8.

18. D'Ambrosio JA, Langlais RP, Young RS. Jaw and skull changes in neurofibromatosis. Oral Surg Oral Med Oral Pathol 1988;66:391-6.

19. Cunha KS, Barboza EP, Dias EP, Oliveira FM. Neurofibromatosis type I with periodontal manifestation. A case report and literature review. Br Dent J 2004;196:457-6o.

20. Bekisz O, Darimont F, Rompen EH. Diffuse but unilateral gingival enlargement associated with von Recklinghausen neurofibromatosis: A case report. J Clin Periodontol 2000;27:361- 5.

21. Bongiorno MR, Pistone G, Aricò $M$. Manifestations of the tongue in Neurofibromatosis type 1. Oral Dis 2006;12:125-9. 22. Apostolidis C, Anterriotis D, Rapidis AD, Angelopoulos AP. Solitary intraosseous neurofibroma of the inferior alveolar nerve:Report of a case. J Oral Maxillofac Surg 2001;59:232-5.

23. Suragimath A, Bijjargi SC, Sande AR, Patil VS. Oral manifestations in neurofibromatosis type I: A case report. J Indian Acad Oral Med Radiol 2014;26:241-4.

24. Friedrich RE, Giese M, Schmelzle R, Mautner VF, Scheuer HA. Jaw malformations plus displacement and numerical aberrations of teeth in neurofibromatosis type 1 : a descriptive analysis of 48 patients based on panoramic radiographs and oral findings. J Cranio Maxillofac Surg 2003;31:1-9.

25. Holtzman L. Radiographic manifestation and treatment consideration in a case of multiple neurofibromatosis. J Endod 1998;24:442-3.

26. White SC, Pharoh MJ. Oral radiology principles and interpretation. 6th ed. Louis: Mosby com; 2009. 
Source of support: Nil, Conflict of interest: None declared

Cite this article as:

Jain M, Jain SD, Gupta P. Bizarre Radiographic Finding of Intraoral

Neurofibroma: A Case Report. Int Healthcare Res J 2018;2(4):92-97. doi:

10.26440/IHRJ/02_04/183

\section{AUTHOR AFFILIATIONS:}

1. Senior Lecturer, Department of Oral Medicine and Radiology, J N Kapoor DAV(C) Dental College, Yamuna Nagar, Haryana

2. Senior Lecturer, Department of Prosthodontics, Yamuna Dental College and Research, Yamunanagar, Haryana, India

3. Consultant Radiologist, Insight CBCT Centre, Pune, Maharashtra, India

\section{Corresponding Author:}

Dr. Saloni Deol Jain

Senior Lecturer

Department of Prosthodontics

Yamuna Dental College and Research

Yamunanagar, Haryana, India
For article enquiry/author contact details, e-mail at: manuscriptenquiry.ihrj@gmail.com
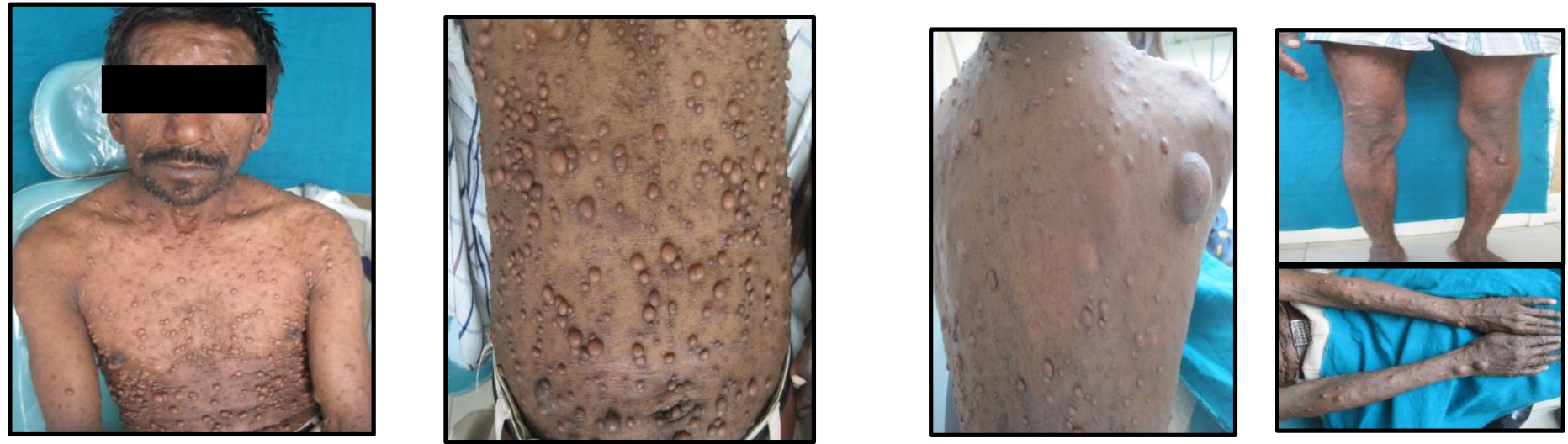

Figure 1,2,3\&4: Presence of a large nodular growth of the skin varying in size was present throughout the body. A brownish small macular appearance was also observed all over the body along with the presence of café-au-lait spots over the trunk area

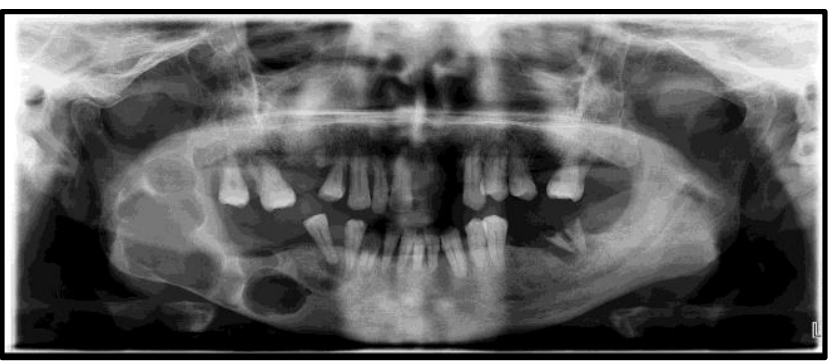

Figure 5. OPG revealing multiple unilocular and multilocular well defined radiolucencies

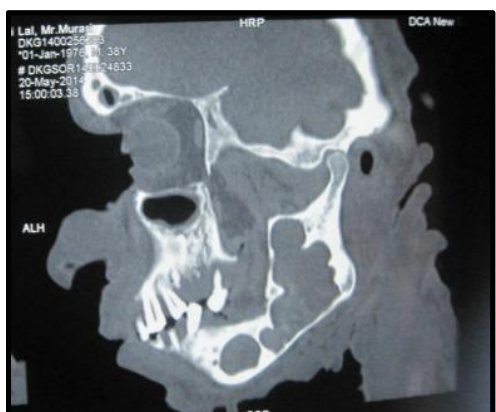

Figure 6. CT of the face and neck region reveals a well-defined radiolucency with respect to the mandibular nerve 

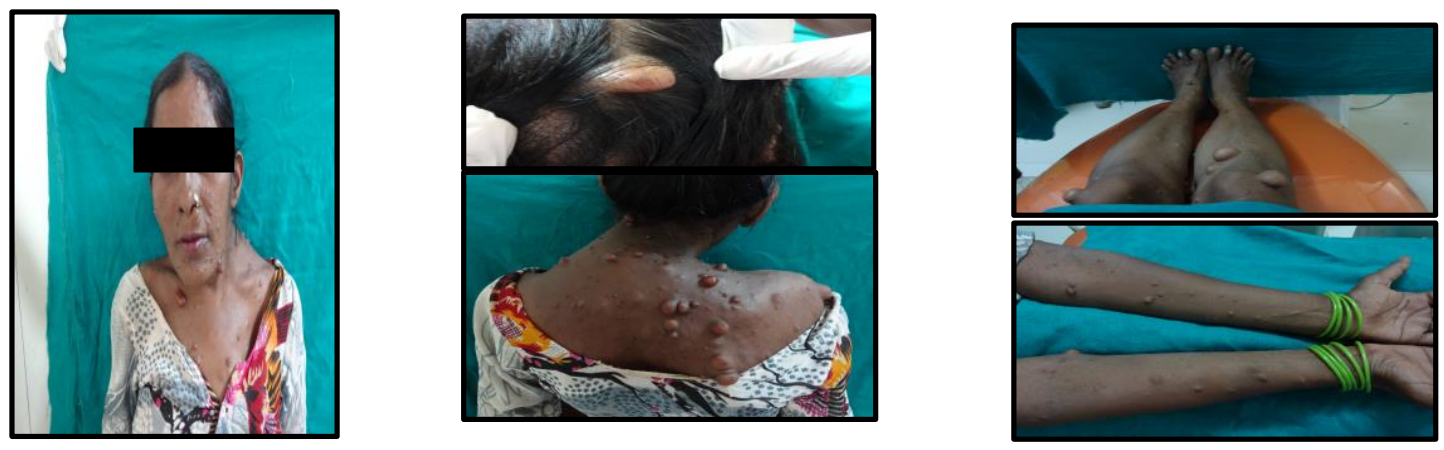

Figure $\mathbf{7}$ a,b,c: Presence of multiple sessile to pedunculated nodular growth was present over the whole body with deviation of head to the right.

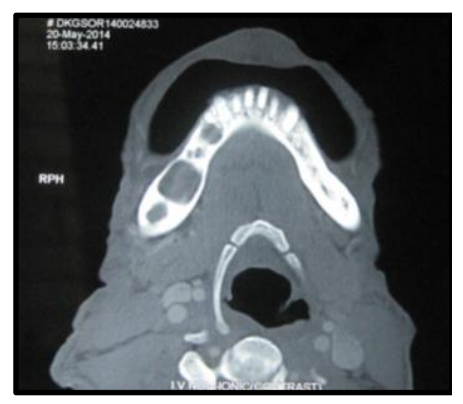

Figure 8: Figure 8. PA view of the head and neck and chest $\mathrm{x}-$ ray suggestive of cranio-vertebral anomalies. 